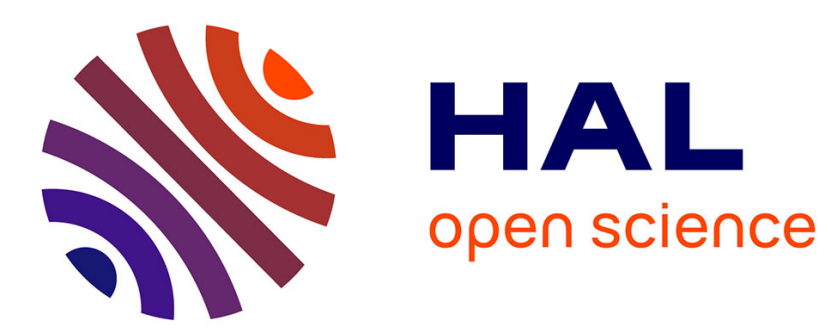

\title{
Worldwide Sourcing Planning at Solutia's Glass Interlayer Products Division
}

Baptiste Lebreton, Luk N. Van Wassenhove, Roger Bloemen

\section{To cite this version:}

Baptiste Lebreton, Luk N. Van Wassenhove, Roger Bloemen. Worldwide Sourcing Planning at Solutia's Glass Interlayer Products Division. International Journal of Production Research, 2009, 48 (03), pp.801-819. 10.1080/00207540802448874 . hal-00547667

\section{HAL Id: hal-00547667 https://hal.science/hal-00547667}

Submitted on 17 Dec 2010

HAL is a multi-disciplinary open access archive for the deposit and dissemination of scientific research documents, whether they are published or not. The documents may come from teaching and research institutions in France or abroad, or from public or private research centers.
L'archive ouverte pluridisciplinaire HAL, est destinée au dépôt et à la diffusion de documents scientifiques de niveau recherche, publiés ou non, émanant des établissements d'enseignement et de recherche français ou étrangers, des laboratoires publics ou privés. 


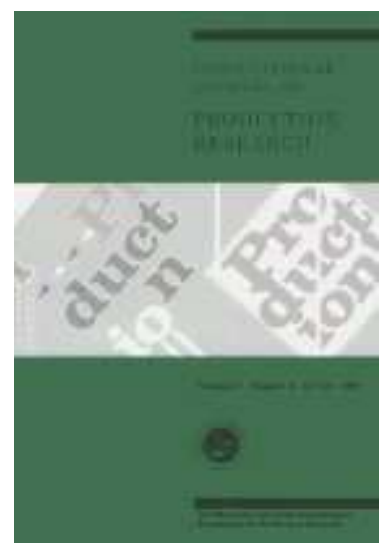

Worldwide Sourcing Planning at Solutia's Glass Interlayer Products Division

\begin{tabular}{|r|l|}
\hline Journal: & International Journal of Production Research \\
\hline Manuscript ID: & TPRS-2008-IJPR-0018.R1 \\
\hline Manuscript Type: & Original Manuscript \\
\hline Author: & $19-$ Aug-2008 \\
\hline Complete List of Authors: & $\begin{array}{l}\text { Lebreton, Baptiste; INSEAD, TOM } \\
\text { Wassenhove, Luk } \\
\text { Bloemen, Roger; Solutia, Saflex }\end{array}$ \\
\hline & $\begin{array}{l}\text { CAPACITY PLANNING, ENTERPRISE RESOURCE PLANNING, GLOBAL } \\
\text { MANUFACTURING, HUMAN-COMPUTER INTERACTION, } \\
\text { INFORMATION SYSTEMS, LINEAR PROGRAMMING, MRP2, } \\
\text { OPERATIONS PLANNING, SUPPLY CHAIN MANAGEMENT }\end{array}$ \\
\hline Keywords (user): & CAPACITY PLANNING, ENTERPRISE RESOURCE PLANNING \\
\hline \multicolumn{2}{|l}{} \\
\hline $\begin{array}{l}\text { Note: The following files were submitted by the author for peer review, but cannot be converted } \\
\text { to PDF. You must view these files (e.g. movies) online. }\end{array}$ \\
\hline LebBloWas07_v3.tex
\end{tabular}

\section{S) ScholaroNE \\ Manuscript Central}




\title{
Worldwide Sourcing Planning at Solutia's Glass Interlayer Products Division
}

\author{
Baptiste G.M. Lebreton, Luk N. Van Wassenhove, \\ INSEAD, Fontainebleau, France \\ Roger R. Bloemen, Solutia N.V., Belgium
}

August 17, 2008

\begin{abstract}
The article describes the realization of an optimization project by a global chemical manufacturer with the objective to develop and implement a supply chain coordination tool. After a presentation of the current supply chain and the challenges faced by Solutia prior to the optimization project, we provide an overview of the mathematical model depicting the company's worldwide production network. We then provide insight into the lessons learned by both optimization team and supply chain managers. In addition to the financial benefits, the project contributed to structure the scattered knowledge around a complex supply chain. We also address the shortcomings of ERP systems when it comes to providing reliable planning data and, in this context, draw parallels between optimization and software development projects.
\end{abstract}

\section{Introduction}

Solutia, a spin-off of Monsanto's former chemical activities with headquarters in St Louis (MO), is the main manufacturer of polyvinyl butyral (PVB) films for glass interlayer applications worldwide. The annual turnover of Solutia's glass interlayer products, which encompasses among others the sales of all PVB-related products, amounted to more than 650 million US dollars in 2006 and has been steadily growing for the last 20 years. Solutia is vertically integrated and produces raw materials such as PVB resins, plasticizers and specialty resins as well as the PVB films used by laminators as interlayer in their automotive and architectural glazing applications.

The outstanding growth of the plastics interlayer division stems mostly from the physical properties of polyvinyl butyral. Due to their adhesive properties, PVB films strengthen laminated glass and bond glass surfaces together even after a shock. With the rising relevance of safety concerns in both automotive and architectural applications, this feature has become one of the main drivers for the development of adhesive interlayers by laminators. Next to these safety concerns, PVB sheets also provide further means for laminators to add specific features to their glasses such as colors or acoustics and UV filtering properties.

Solutia is currently operating under Chapter 11 protection. The outcome is a fundamental reorganization of the company focusing on substantial profitability improvements. This issue is further aggravated by the fact that Solutia has not been able to pass the recent oil price increases to its customers. Given this, Solutia's PVB division is required to rethink its current sourcing 
strategy with the objective to compensate the increasing raw material costs by an improved organization and utilization of its worldwide assets.

Like many chemical companies, Solutia acts in an international environment and has already started to expand its supply chain towards developing markets in the eighties. The current supply chain of the PVB division, as depicted in figure 1, can be divided into four main production steps dispatched over more than fifteen lines and seven countries (Belgium, UK, USA, Mexico, Brazil, Singapore and China).

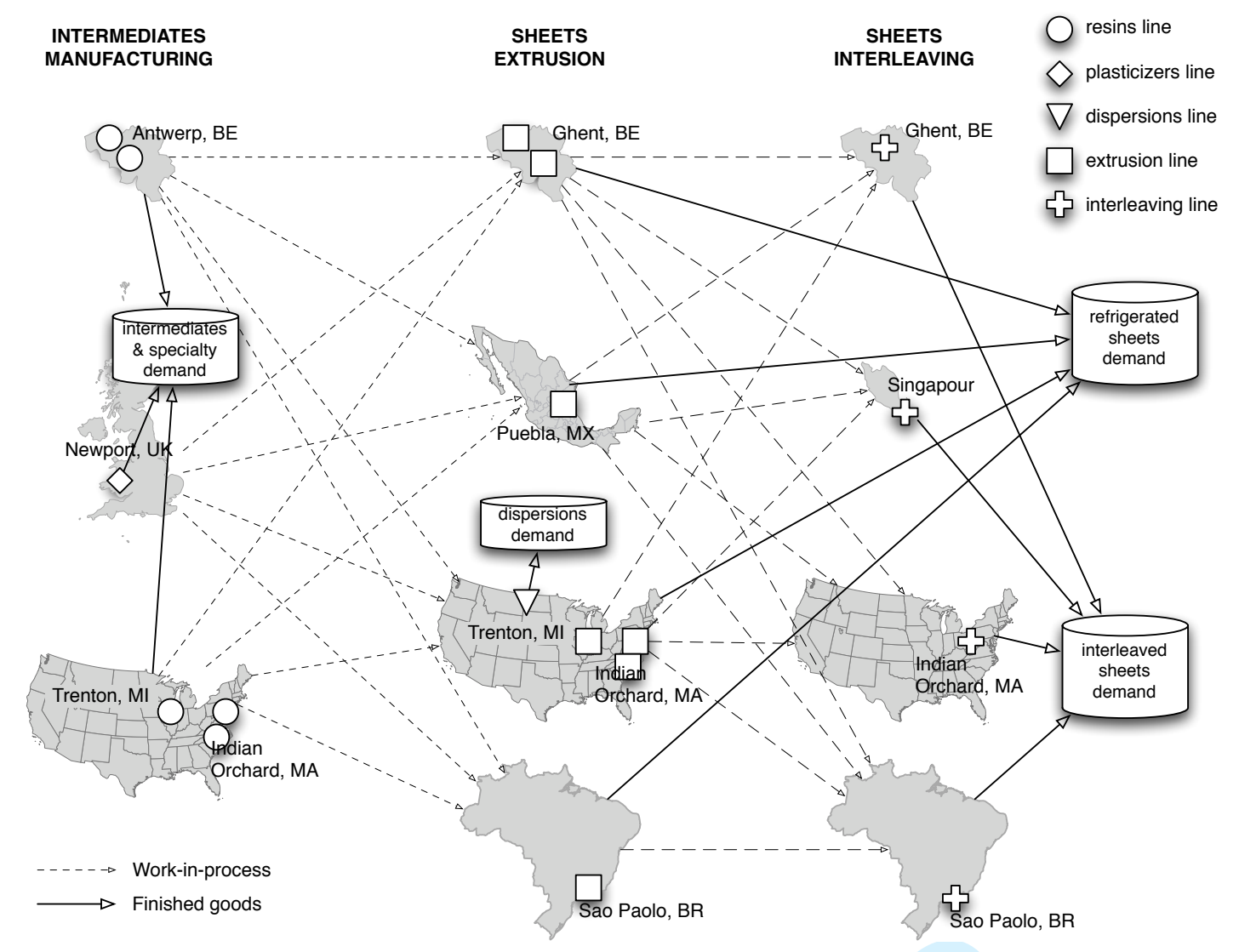

Figure 1: Glass interlayer supply chain network: Intermediates (resins and plasticizers) are used in the extrusion process to produce PVB sheets, sold on the market or mixed for dispersions manufacturing. The PVB sheets can be either shipped refrigerated to the customer or be interleaved.

1. Intermediates manufacturing. This step is concerned with the production of generic PVB resins and plasticizers which are either used internally or sold. Specialty PVB resins are sold on the open market as input for the manufacturing of adhesive products of all kinds but not related to classical laminating applications.

2. Dispersions manufacturing. Solutia is able to process generic resins to latex-like products used, among others, for the corrosion prevention of metallic surfaces.

3. Extrusion. PVB films are obtained by blending a predefined mix of resins and plasticizers. 
For storage purposes, the films are stored as rolls and have to be refrigerated in order to avoid irreversible polymer bindings which usually take place when the temperature rises above $10^{\circ} \mathrm{C}$.

4. Interleaving. When the logistics infrastructure of a country does not allow a reliable refrigeration of the PVB rolls, an additional sheet is interleaved in the roll to avoid the direct contact between two PVB layers. Thus, the polymer binding process is prevented and the rolls can be stored and transported at ambient temperatures.

Until recently, the business units (raw materials, dispersions and PVB sheets) had been largely managed separately although these units are sharing the same scarce resources (see figure 2 for an overview of the former planning scopes). The sale of additional intermediates such as resins constrains for instance the manufacturing potential of the extrusion process and therefore the potential revenues generated from refrigerated and interleaved PVB sheets.

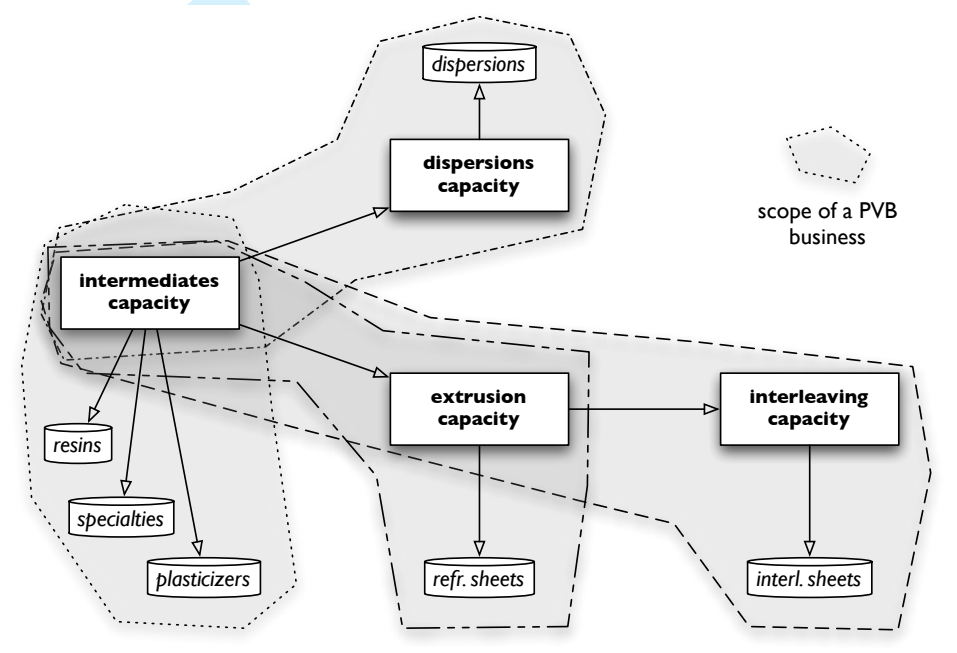

Figure 2: Former planning scope of the PVB businesses: Although the businesses were competing on the same resources, planning was performed separately for each of them.

As a result of this business unit focus, asset optimization took place locally. This situation sometimes led to the acceptance of contracts that were profitable when taken in isolation but preempting sales of more profitable products. Asset trade-offs were made during the global sales and operations planning meetings, but the decision process was hindered by lack of accurate global optimization capability. The planning process, which was spreadsheet-driven, had limited global integration by product category and world area. Due to the strong interdependencies between the different product categories, a comprehensive approach had to be developed to ensure that the resource allocation maximized the profits of the PVB division as a whole. The supply chain managers needed a tool to rely on facts instead of assumptions based on limited spreadsheet simulation capability.

The lack of integrated supply chain optimization capability resulted in the ad hoc settlement of a worldwide sourcing policy. This sourcing policy was far from optimal, among others because the center of gravity of the demand had changed in recent years. To maximize the production line 
output with respect to scarce capacity, the PVB division applied the plant specialization concept. Products were allocated to specific production units around the world. Although this strategy was very successful in increasing service and line yields, it turned out to be counterproductive for the realization of savings on freight and custom duties. Here again, supply chain managers have to balance between conflicting objectives and need a comprehensive framework in order to cope with the inherent complexity of the PVB supply chain.

In this context, Solutia's new supply chain director got in touch with INSEAD early 2005 to develop a sourcing optimization model with respect to the specificities mentioned above. In line with Chapter 11's reorganization plan, Solutia's requirements were twofold. First, a supply chain-wide sourcing plan maximizing the contribution of the PVB division had to be provided. Furthermore, the use of mathematical methods should provide insights into the profitability and the supply chain impact of every supply contract. The identification and re-negotiation of low income businesses was one of the main objectives of Solutia's management.

\section{Solutia's Global Sourcing Model}

\section{Literature overview}

Solutia's global sourcing problem belongs to the Master Planning process in the supply chain planning literature. According to Rohde and Wagner (2005), Master Planning deals with the coordination of flows from procurement of raw materials to the distribution of finished goods. This coordination is performed by determining how much capacity should be reserved for each product group and how much inventories should be built to ensure optimal levels of supply. The first models applied to the industry were developed in the 1970s. Hax and Meal (1975) publication of a hierarchical planning system for a tire manufacturer, including a capacity planning model, initiated a stream of further publications. Glover et al. (1979) present a LP model to minimize production and inventory costs in an industry with a seasonal demand pattern. Liberatore and Miller (1985) develop a hierarchical planning system for an American manufacturer of ceramic tiles. The authors break down the master planning problem into a product-plant assignment model and a family scheduling model (campaign planning). Stadtler (1988) drafts a concept to run a hierarchical production planning system at a German consumer goods manufacturer. The author uses lagrangean techniques to determine optimal lot sizes of product families in a multilevel manufacturing environment.

While most of the publications mentioned above needed to break the master planning problem into sub-problems, recent industrial applications point out that complex global supply chains can be planned within one optimization model. Computational power and memory limitations do not appear to be a hurdle anymore for most of the master planning problems. Arntzen et al. (1995) optimize the worldwide component procurement and assembly of computer devices at Digital Equipment Corporation. Bermon and Hood (1999) and Karabuk and Wu (2003) develop a standard model for planning capacity based on projects at semi-conductors manufacturers. Denton et al. (2006) use a mix of linear programming and custom heuristics to optimize the manufacturing and distribution processes at IBM semi-conductors. The model includes lot sizing decisions, external procurement alternatives as well as product substitutions for wafers. The model minimizes supply chain costs while penalizing unfulfilled demand. The penalty depends on the company's customer priorities.

In the chemical industry, Tyagi et al. (2004) develop a network flow model to maximize 
supply chain contribution at General Electric's plastics division. The model developed for Solutia will extend the approach taken by Tyagi et al. First, we allow the use of a flexible mix of intermediates for the production of PVB sheets. Furthermore, we take single sourcing constraints into account as automotive and architectural laminators do not accept frequent sourcing changes. Recently, Dauzere-Peres et al. (2007) present a decision support system implemented at Omya Hustadmarmor, a calcium carbonate slurry producer. The underlying planning model contributes to improve the coordination between manufacturing and distribution and thus to reduce distribution costs.

\section{Global sourcing model}

Solutia's global sourcing model maximizes the overall contribution of the PVB supply chain. The resulting production and distribution plan is used as a basis to define the length and sequence of the campaigns on each production line. The model's variables and parameters are illustrated in figure 3. The margin is expressed for the four product groups (intermediate with index sets $m$ and $r$, dispersion - index $d$, refrigerated and interleaving products - index sets $p_{e}$ and $p_{o}$ ). A transfer pricing scheme is also included to assess accurately custom duties. For each process, three cost blocks are deducted from the external revenues (spr) and internal revenues (tpr): variable production costs (var), freight costs (fre) and custom duties (dty $\cdot s p r)$. Duties are expressed in percentage of the value imported while the prices are duty paid.

For reasons of tractability, we have left duty drawback and relief effects out of the analysis and refer to Arntzen et al. (1995) or Vidal and Goetschalckx (2001) for ways to integrate duties in a more accurate but also more complex fashion. We note that these effects would occur in Solutia's supply chain when raw materials from Europe would be shipped to an other region (Asia, NAFTA, South America) for extrusion and then returned to Europe. It is clear that the contribution maximization objective will aim at avoiding such expensive product transfers between world regions. Thus, the consequences of this simplification on the model's accuracy are very limited. 
The model's constraints can be gathered into three groups: capacity, demand and sourcing constraints.

- Capacity. The scarce capacity, expressed in days per quarter (cap), is consumed by intermediates $(I N T)$, dispersion $(D I S)$, refrigerated sheets $(E X T)$ and interleaved sheets $(O F L)$. With help of the dual values on the capacity constraints, Solutia's managers are able to estimate the financial impact of additional capacity on every line and thus to focus their productivity improvement efforts on the right resources. Equations 6 to 9 in the appendix express the manufacturing capacity constraints, parameter rate describing the throughput per line and day.

- Demand. The demand for intermediates, dispersions and PVB sheets needs to be fulfilled. Nevertheless, in order to identify the products which should be pushed, demand is allowed to vary between a lower $l b$ and an upper bound $u b$ (see also equations 10 to 13). Every product represents a combination of a customer and a raw material or formulation. This level of granularity leads to more than 3,000 products for the planning model.

- Sourcing requirements. Every PVB sheet formulation has a specific raw material mix that can be modified within a small range in order to find a cost-efficient sourcing of the so-called intermediates. Equations 15 and 16 in appendix sets lower and upper bounds for the use of specific resins in a PVB film $p$ while equation 17 expresses the total resin requirements for a this specific product $p$. After some initial runs of the model, the decision was taken to impose single sourcing policies in order to consolidate deliveries and stabilize the product routings (eq. 18 to 20 ). 
Due to its classical multi-commodity network flow structure with linear costs, the original sourcing model allowing multiple sourcing was solved to optimality within 5 seconds by the dual simplex algorithm. The model contained 40,000 variables and 12,000 constraints after preprocessing (180,000 variables and 60,000 constraints initially). Hence, given the problem's size, more elaborated methods such as column generation were not necessary (see for instance Barnhart et al., 1995 or Holmberg et al. 2003). The addition of a single sourcing constraint for extruded sheets obviously extended the computation time. However, the model is still solved to optimality in less than 30 minutes with the help of an open-source solver (GLPK 4.18, see Makhorine, 2007). A complete model description is provided in appendix.

\section{Managerial Insights}

\section{Optimization as a knowledge acquisition process}

The decentralized planning had prevented Solutia's decision makers from obtaining an unbiased and global view of the supply chain dynamics. This situation had in some cases led to suboptimal decisions as the managers lacked the interactions with the other PVB businesses. Moreover, their knowledge about the costs and technologies of the other PVB businesses was not integrated into the planning process. The global sourcing model obliged the supply chain stakeholders (plant managers, shipment services, sales) to include this information in a structured way. This structuration effort, as well as the discussions resulting from the optimization runs, have contributed to create unbiased knowledge on the basis of traceable inputs. For the first time, synthetic supply chain-wide data (i.e. prices, costs and technological issues) have been made available at a central point to support the decision-making process.

The supply chain decisions can now be quantified and their impact on the overall chain immediately assessed with the help of the reporting tool embedded into the custom MS Excel template. In addition to these knowledge creation effects, the sourcing model has significantly helped improve the supply chain's contribution through making the products in the most cost effective location and the stepwise renegotiation of unprofitable businesses identified in the analysis.

Nevertheless, one of the main benefits for the supply chain team is situated in the daily planning process. The existence of a comprehensive and relatively unbiased planning framework helps avoiding unfruitful discussions within the company concerning the sourcing strategy or the product mix. To quote the global supply chain planner, "you have a question, you push a button and obtain immediately some valuable insight. This saves you a bunch of meetings".

One compelling example in the project was the discussion around two variants of the same product with similar demand (called $A$ and $B$ ). $A$ was sourced from Europe although the main demand was in the US and Canada. $B$ was sourced from the US although the main market was Germany and the Benelux. In fact, each product could have been produced locally ( $A$ in the US and $B$ in Belgium) but for technical reasons, the decision had been taken a couple of years ago to assign $A$ to the US because of scarce capacities in Europe. By comparing the historical sourcing with the model's results, the supply chain director (SCD) asked his team (T) during a meeting: SCD: "So we're shipping 400,000 sqm over the ocean right now for this product although we could make the product locally?", T: "Yes but this is a sourcing rule that is important, we cannot easily change that and we are always short on capacity. Our customers will have to qualify the products again since they're coming from another plant.", SCD: "The 
model says that we have the capacity and thus we can do it. All in all, we save good money so let's start it immediately. Discussion closed.". Although the savings achieved by the model are difficult to segregate from the benefits of the supply chain reorganization efforts, the use of linear programming has provided a neutral base for the decision-making process.

\section{How much optimization is in an optimization project? A tentative quantifi- cation}

The experience gained from former optimization projects already indicated that the time spent for true optimization is usually minor. From the beginning, we documented in this project every half-day spent on eight core project activities (depicted in figure 4). First, the problem as well as the scope of the supply chain analysis had to be explicitly defined. Thanks to the engineering background of the supply chain managers, this phase took only $5 \%$ of the total project time. The mathematical model has passed through three revisions on which we spent only $2 \%$ of the project time. Here, the modification efforts were limited as the scope had been clearly defined at the project start. With respect to the limited financial resources and the legacy concerns, the team decided to use open source solvers instead of powerful professional applications such as ILOG Cplex or LINDO. Solvers directly embedded into MS Excel were also not desired as the Solutia managers wanted to review and potentially adapt the mathematical model after the project's end. Finally, the GNU Linear Programming Kit (GLPK version 4.9) was chosen for its powerful modelling language MathProg, a derived subset from AMPL, which allowed a quick and understandable model implementation. The lack of flexibility of GLPK concerning the results display required the development of unplanned i/o routines between the MS Excel input template and the LP solver. Consequently, the model implementation as well as the model debugging phase took longer than expected but amounted finally to only $6 \%$ of the total time (seven man-days). The project's conceptual phase represented therefore only $13 \%$ of the total project efforts.

Although Solutia runs a company-wide SAP system, the data processing phase took $45 \%$ of the project time. The raw data was easily accessible, however, the cost rates obtained were based on averages and did not provide the data quality required for a reliable optimization of the global sourcing. In order to catch the dynamics of the supply chain and to obtain the decision-relevant data, the optimization team had to get in touch with several specialists in every PVB business to iron out the assumptions behind the available freight and duty rates. The strong management commitment for the project was in this context critical to obtain a quick feedback from the specialists. While the data collection took one fifth of the project time, the data processing, i.e. the preparation of the data for optimization purposes took approximatively another fifth of the time (also including comprehensive plausibility checking and reporting routines). These unexpected efforts stem mostly from the fact that the minor model revisions highly impacted the data structure and, as a consequence, required a redefinition of the database queries and raw files processing.

Concerning the true optimization time, the preprocessing engine of GLPK reduced the problem size to about 40,000 variables and 12,000 constraints. Logically, the total project time spent on computing amounts to only $3 \%$ since the linear programming problem was usually solved within 5 seconds on a Macintosh MacBookPro with $2.1 \mathrm{GHz}$ and 1.5 GB RAM. The introduction of a single sourcing constraint to the extruded products has extended the computation time to 30 minutes per run. The efforts researchers might spend on the improvement of current 
linear programming algorithms clearly outweigh the additional benefits for the final users. The development of straightforward data retrieval and manipulation routines to support the optimization team along model revisions might be a much more promising means for open-source optimization software to grow in a corporate environment.

The analysis phase per se took $15 \%$ of the time (18 days) also including the interactions with the supply chain managers. As the optimization results convinced the managers of the utility of running a global sourcing optimization on a quarterly basis, we needed to adapt the existing application for users without advanced mathematical knowledge and ensure that the application would run on every computer without time-consuming installation routines. Furthermore, a complete documentation needed to be appended to the sourcing application so that the legacy phase took finally 1.5 months to complete. In a nutshell, model design, development, testing and optimization took less than $16 \%$ of the total project time.

\section{The ERP pitfall}

The high level of detail initially requested had been justified by Solutia's belief that the existing SAP system would provide the model input in one click. Unfortunately, the cost data retrieved from the database turned out to be too approximated to be trustworthy. In classical ERP systems, each shipment is broken down into freight legs which very often have a different composition (see figure 5). Shipments can be consolidated in a regional warehouse prior to being dispatched to a local distribution center or sent directly in case of full truck loads (or in case of urgent shipments). After the first automated queries, it became obvious that some freight routes were either priced too low (e.g. bulk shipments of leftovers) or too high (e.g. urgent shipments 
from alternative plants) as these shipments had formerly been of exceptional nature. Furthermore, each product could follow several potential paths, with different loads and container costs. Given the variability among shipments, the decision was taken to identify one ideal product path for each plant/product/customer combination and to retrieve the total shipment costs for each corresponding ideal leg. Then, the total costs were divided by the average shipment quantities to obtain a tractable freight cost figure per square meter PVB sheet. Thus, the computation of the freight costs had to be made on a case-by-case basis relying on expert knowledge rather than on meaningless averages or non-representative ERP data.

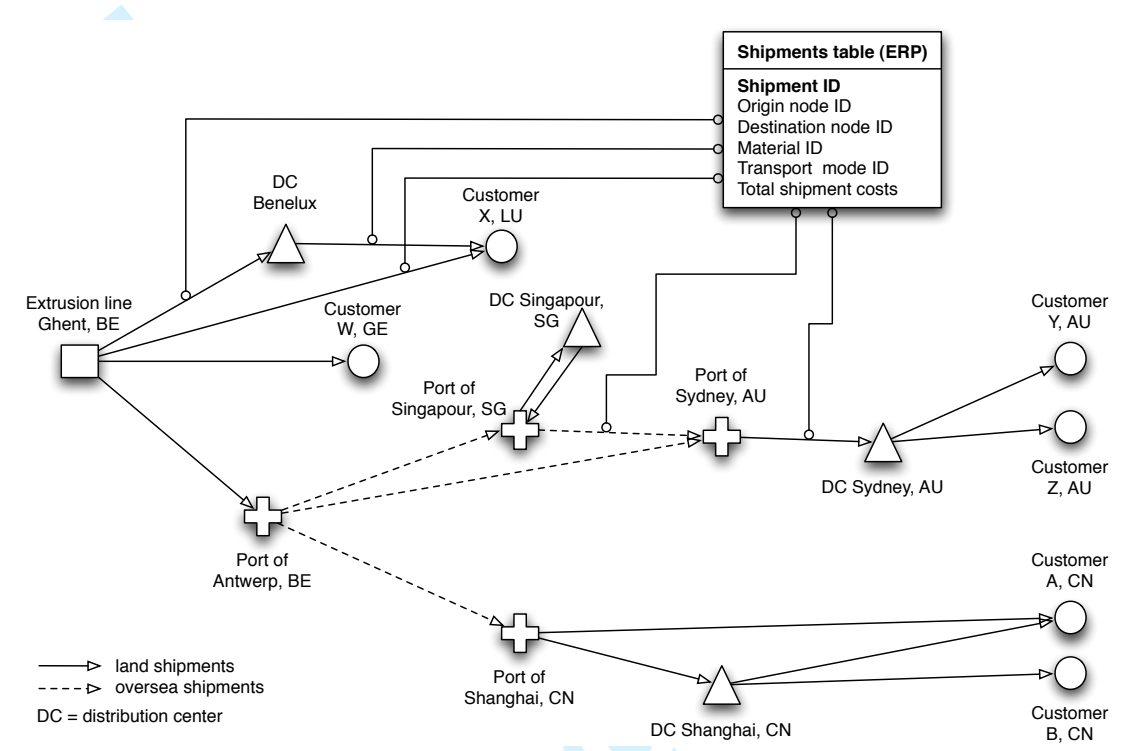

Figure 5: To retrieve the freight costs per square meter sheet from an extrusion line (here Ghent) to final customers, a case by case analysis had to be performed in order to determine the total costs for all freight legs and the average loads of each shipment.

Due to the multitude of stock keeping units retrieved, the average rates obtained for the manufacturing costs and the custom duties needed to be cleaned before use but could not be checked in detail before the first optimization runs. Unfortunately, data inconsistencies led to unstable sourcing results but the schedule was too short to allow spending much time on troubleshooting. The team decided therefore to reduce the model complexity and to reduce the initial customer/formulation combinations to formulation/world region combinations. The suppression of the customer information simplified the model at the expense of accuracy but enabled the team to improve the model's stability and to update the data previously inducing counter-intuitive results. This simplification delivered reliable results for the sourcing optimization before the deadline and allowed the team to perform insightful profitability assessments by product formulation and world region.

The experience and knowledge gained from the first optimization results and their analysis increased the commitment of Solutia's managers and specialists to the model. The frequent interactions between the optimization team and the information owners concerning the optimization outcome fostered Solutia's understanding of the potential utility of comprehensive optimization techniques. The limitation of current sourcing practices became obvious and could be quanti- 
fied, however, in some cases the results were counter-intuitive for the stakeholders providing the data. Interestingly, these contradictions were mostly due to the lack of data specification in the information retrieval process. Thanks to the managers' commitment, the specialists' awareness to prepare the data in an accurate way raised strongly after the first discussions. The availability of SAP would not have allowed data providers to benefit from information asymmetry and Solutia's cooperative corporate culture would also have penalized such behaviors.

Consequently, we were able to reintroduce the customer dimension in the global sourcing analysis since both managers and data providers were willing to assess the exact value generated by each PVB customer. To overcome the initial model's limitations, the Solutia team was now aware of the required data granularity to fulfill the assessment objectives. With the redefinition of the business data in the project's third phase (see figure 6), the trade-off between level of detail and model accuracy has been successfully tackled.

To summarize, the existence of SAP repositories has proven to be a great help for retrieving a wide range of parameters in a short lapse of time. Nevertheless, mathematical approaches require data preparation efforts that should not be underestimated, with or without SAP R/3. In the present case, the theoretical availability of data was no guarantee for reliable results as the figures were not always matching the parameters they should represent.

\section{Optimization projects do not follow a strict sequential development}

In theory, optimization projects should start with a requirements phase defining the objective of the customer as well as the scope of the project. Once these requirements are set, the optimization tool's architecture is designed and coded. The final application is tested and finally released to the customers. These steps should be sequential with clear milestones, following a so-called waterfall model (Royce, 1970). Interestingly, this approach for developing software applications have proven to be very unproductive. One of the main reasons stems from the difficulty of final users to define clearly their requirements at the beginning of the project. Many 
requirements are defined when users give feedback on a prototype. In this context, the design of software applications might have to be modified during the project. Research in software development have concluded that, although software development has to be divided into phases, these phases have to be run in parallel, with different levels of intensity during the project (see e.g. the Rational Unified Process, Jacobson et al., 1999).

Significant efforts were spent in this optimization project to retrieve data that was not initially in the scope of the model. Figuring out that the required additional data was not available obliged the optimization team to also adapt its modeling approach. Hence, the project team did not only spent most of its time dealing with non-optimization issues, it was also obliged to modify the scope of the project and redesign the optimization model. With respect to the task breakdown described earlier in this section, one can draw some similarities between optimization projects and classical software projects. The model passed through numerous revisions making a strictly sequential model development with feedback loops useless. The requirements of the optimization project evolved over time depending on the initial optimization results. Furthermore, although Solutia's supply chain managers were familiar with linear programming techniques and had already used them for local applications, several aspects that had been initially left out of the analysis turned out to be critical for the reliability and credibility of the optimization results.

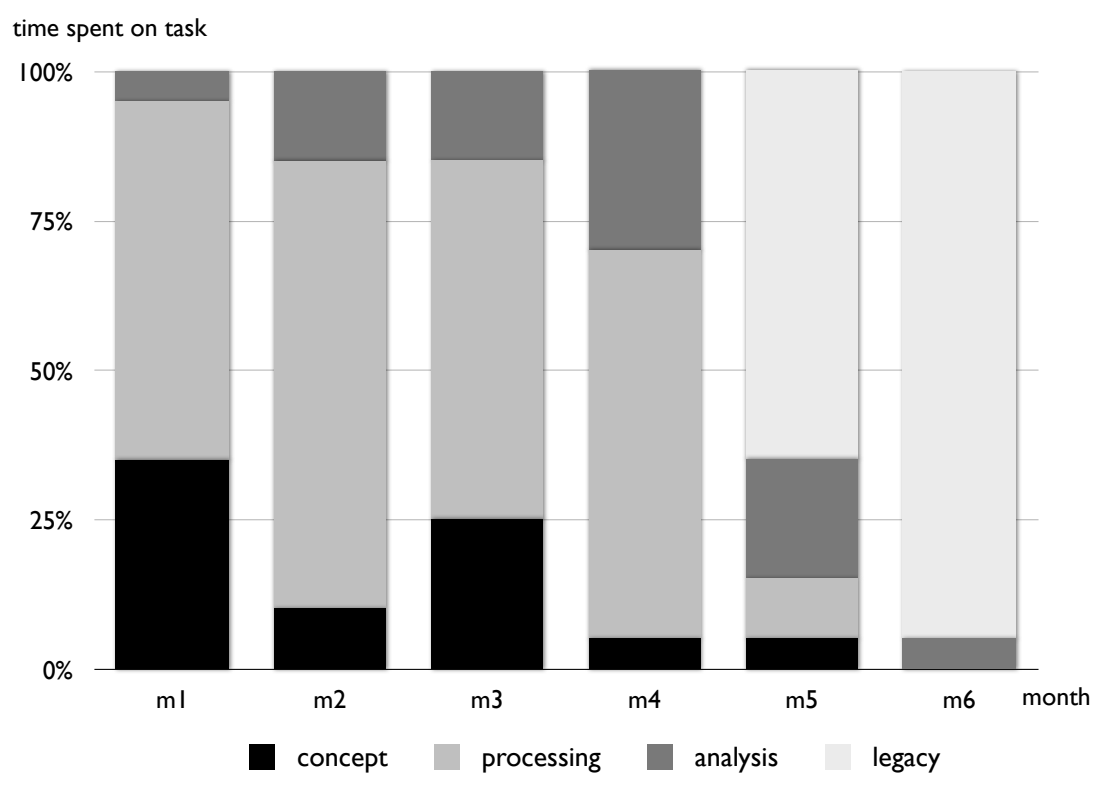

Figure 7: Task evolution over the project horizon: Optimization projects require an iterative approach instead of a waterfall approach.

Similarly to the Rational Unified Process, the core project activities of the optimization project (conceptual, processing and analysis tasks) have been performed simultaneously but with a different intensity (as depicted in figure 7). The main difference between software development and optimization projects is located in the construction phase of the project. Unlike software, most mathematical problems in business are very limited in scope and complexity so that the true product development time is much shorter than in classical software projects. 
Interestingly, the detailled breakdown of the project tasks also underlines the gap between what open source solvers can provide (optimize a predefined mathematical problem) and what they could be able to do, i.e., manage models and data in an ever-changing environment. Open source optimization software still misses advanced information retrieval and processing routines to ease the optimization workflow while remaining flexible enough for changing requirements.

Nevertheless, these tools provide a relatively cheap and very efficient means to develop a pilot application and gain experience on how to retrieve the planning data and align the organization. The preliminary specification efforts contribute to reduce the costs to roll out a professional planning suite as the consultants implementing professional applications already get a clear picture on how the supply chain stakeholders are working and what they are expecting.

\section{Conclusion}

The optimization project presented in this paper is a very typical one with respect to issues faced and benefits generated. The application of mathematical methods to complex planning situations such as Solutia's supply chain required a structured approach that has paid off.

On the one hand, significant savings were achieved through a better utilization of the assets and the avoidance of local optimization arbitrages. This project was a main part of Solutia's reorganization concept and contributed to improve the EBIT of the PVB business by a significant undisclosed amount. Since there are only a few players, the company cannot disclose exact figures. On the other hand, the information structuration efforts have benefited all local managers who had the opportunity to understand the economics of the other supply chain stakeholders.

The problem faced by Solutia is typical for a large number of medium-sized or even smaller companies (SMEs) facing globalization, shifting markets and increasing pressures on profitability. These companies quickly need to transit to the age of insightful global sourcing models. Of course, large companies had both the need and the required resources to make this transition years ago. The pervasion of ERP software like SAP now provides the opportunity for SMEs to follow suit. This opportunity is amplified by readily available LP/MIP solvers.

However, this problem illustrates that the availability of ERP and optimization software is a necessary but not a sufficient condition for sourcing optimization in SMEs. The management team needs to be willing to embark on a learning (knowledge acquisition) process. Even though the actual savings in this study were very substantial and even crucial for a company under Chapter 11, the indirect future savings because of the management team's learning about their global supply chain are probably even larger. When used properly, the ERP/optimization software couple is a very powerful learning tool.

This article illustrates that in most cases, there will be a tedious first step requiring the model to be formulated at the correct level of aggregation, with reliable data. This step requires parallel development, like software projects. Figures 4 and 7 clearly document that the actual optimization time is negligible compared to other tasks in introducing model-based decision making.

Finally, we also point out a common pitfall of ERP implementations. The latter's success is often measured by means of the time required to go live. As an ERP implementation cannot be immediately judged on its ability to increase a company's competitiveness, implementation time is therefore the only performance indicator applicable for both vendor and consultants rolling out the solution. However, the quality of the implementation depends heavily on the 
involvement of the future users of the ERP solution.

Especially in SMEs, there may be insufficient time and resources to specify a data structure that perfectly fits the business-specific planning requirements and to fill the system with reliable data. Let's put in some averages or estimates now, we'll enter the correct data later, is a frequently heard phrase during ERP implementations under this pressure. Of course, this will act as a boomerang as soon as one starts using ERP data for optimization purposes. It is easy for companies to get trapped in this illusion of control, of having all data available on-line in an ERP system. One could just call this a modern and dangerous version of the old garbage-in, garbage-out rule for optimization models.

Concluding, this paper discussed the successful journey of Solutia N.V., a company and management team eager to exploit modern ERP and mixed integer programming software to learn about its complex global supply chain, as well as the difficulties encountered along the way. Researchers and software developers could add a lot of value in helping remove these difficulties.

\section{References}

[1] Arntzen BC, Brown GG, Harrison TP and LL Trafton (1995) Global Supply Chain Management at Digital Equipment Corporation. Interfaces, 25(1):69-93.

[2] Barnhart C, Hane CA, Johnson EL and G Sigismondi (1995) A Column Generation and Partitioning Approach for Multi-Commodity Flow Problems. Telecommunication Systems, $3: 239-258$.

[3] Bermon S and SJ Hood (1999) Capacity Optimization Planning System. Interfaces, $29(5): 31-51$.

[4] Dauzere-Peres S, Nordli A, Olstad A, Haugen K, Koester U, Myrstad PO, Teistklub G, Reistad A (2007) Omya Hustadmarmor Optimizes Its Supply Chain for Delivering Calcium Carbonate Slurry to European Paper Manufacturers. Interfaces, 31(7):39-51.

[5] Denton BT, Forrest J and RJ Milne (2006) IBM Solves a Mixed-Integer Program to Optimize Its Semiconductor Supply Chain. Interfaces, 36(5):386-399.

[6] Glover F, Jones G, Klingman D and J Mote (1979) An Integrated Production, Distribution and Inventory Planning System. Interfaces, 9(5):21-35.

[7] Hax AC and HC Meal (1975) Hierarchical Integration of Production Planning and Scheduling. In MA Geisler (ed.): Studies in the Management Sciences, 53-69, North Holland, Amsterdam.

[8] Holmberg K and D Yuan (2003) A Multi-Commodity Network-Flow Problem with Side Constraints on Paths Solved by Column Generation. INFORMS Journal on Computing, 15(1):42-57.

[9] Jacobson I, Booch G and J Rumbaugh (1999) The Unified Software Development Process. Addison-Wesley.

[10] Kallrath J (2002) Gemischt-ganzzahlige Optimierung: Modelle und Anwendungen. Vieweg. 
[11] Karabuk S and SD Wu (2003) Coordinating strategic capacity planning in the semiconductor industry. Operations Reseach 51(6):839-849.

[12] Kilger C (2005) The Definition of a Supply Chain Project. In: Stadtler H and C Kilger, Supply Chain Management and Advanced Planning, 283-302, Springer, 3rd edition.

[13] Liberatore MJ and T Miller (1985) A Hierarchical Production Planning System. Interfaces, 15(4):1-11.

[14] Makhorine A (2007) GLPK 4.18 language manual, GNU foundation.

[15] Rohde J and M Wagner (2005) Master Planning. In: Stadtler H and C Kilger, Supply Chain Management and Advanced Planning, 159-177, Springer, 3rd edition.

[16] Stadtler H (1988) Hierarchische Produktionsplanung bei losweiser Fertigung (Hierarchical planning for batch manufacturing). Physica, Heidelberg.

[17] Tyagi R, Munshaw G, Kalish P and K Akbay (2004) GE Plastics Optimizes Two-Echelon Fulfillment Network at High Performance Polymers Division. Interfaces, 34(5):359-366.

[18] Vidal CJ and M Goetschalckx (2001) A Global Supply Chain Model with Transfer Pricing and Transportation Cost Allocation. European Journal of Operational Research, 129:134158.

\section{Appendix: Global Sourcing Model}

Index sets

$\begin{array}{lll}i \in I & : & \text { intermediate lines } \\ e \in E & : & \text { extrusion lines } \\ o \in O & : & \text { interleaving lines } \\ d \in D & : & \text { dispersion lines } \\ m \in M & : & \text { intermediates } \\ r \in R & : & \text { raw materials (product/customer combination) } \\ s \in S & : & \text { dispersion resins (product/customer combination) } \\ p \in P & : & \text { PVB sheets (product/customer combination) } \\ p_{e} \in P & : & \text { refrigerated sheets } \\ p_{o} \in P & : & \text { interleaved sheets } \\ t \in T & : & \text { quarters }\end{array}$

\section{Variables}

$I N T_{i, e, m, t}^{e x t}: \quad$ quantities of intermediate $m$ produced on intermediate line $i, \quad[\mathrm{~kg}]$ shipped to extrusion line $e$ in quarter $t$

$M A T_{i, r, t} \quad$ : quantities of raw material $r$ produced on intermediate line $i$ to $\quad[\mathrm{kg}]$ meet external demand in quarter $t$

$I N T_{i, d, m, t}^{\text {dis }}: \quad$ quantities of intermediate $m$ produced on intermediate line $i \quad[\mathrm{~kg}]$ shipped to dispersion line $d$ in quarter $t$ 
$D I S_{d, s, t} \quad$ : quantities of dispersion resin $s$ produced on dispersion line $d$ in $\quad[\mathrm{kg}]$ quarter $t$

$E X T_{e, p_{e}, t}: \quad$ quantities of product $p_{e}$ extruded on line $e$ in quarter $t \quad$ [sqm]

$O F L_{e, o, p_{o}, t}: \quad$ quantities of product $p_{o}$ extruded on line $e$, interleaved on line $o$ [sqm] in quarter $t$

\section{Objective function and related financial parameters}

The objective of the worldwide sourcing model is to maximize Solutia's contribution $\left(\Pi^{\text {Solutia }}\right)$ resulting from the consolidation of all PVB businesses' margins.

$$
\begin{array}{rll}
\text { maximize } & ! & \sum_{t} \Pi_{t}^{\text {Solutia }} \\
\text { with } & \Pi_{t}^{\text {Solutia }}=\sum_{i} \pi_{i, t}^{\text {int }}+\sum_{d} \pi_{d, t}^{\text {dis }}+\sum_{e} \pi_{e, t}^{\text {ext }}+\sum_{o} \pi_{o, t}^{o f l}
\end{array}
$$

At each supply chain stage, margins result from removing all exploitation costs (production var, freight fre, duties $d t y$ ) from revenues spr and $t p r$.

$$
\begin{aligned}
& t p r_{m}^{i n t}: \text { internal transfer price for intermediate } m \quad[\$ / \mathrm{kg}] \\
& s p r_{r}^{\text {mat }}: \text { sales price of raw material } r \quad[\$ / \mathrm{kg}] \\
& \operatorname{var}_{i, m}^{i n t}: \quad \text { production costs for intermediate } m \text { on line } i \quad[\$ / \mathrm{kg}] \\
& v_{i, r}^{\text {mat }} \text { : production costs for raw material } r \text { on line } i \quad[\$ / \mathrm{kg}] \\
& f r e_{i, d}^{i t d}: \text { freight costs from intermediate line } i \text { to dispersion line } d \quad[\$ / \mathrm{kg}] \\
& f r e_{i, e}^{i n t}: \text { freight costs from intermediate line } i \text { to extrusion line } e \quad[\$ / \mathrm{kg}] \\
& f r e_{i, r}^{m a t}: \quad \text { freight costs from intermediate line } i \text { for raw material } r \quad[\$ / \mathrm{kg}] \\
& d t y_{i, d}^{i t d}: \text { duty rate from intermediate line } i \text { to dispersion line } d \quad[\%] \\
& d t y_{i, e}^{i n t}: \text { duty rate from intermediate line } i \text { to extrusion plant } e \text { [\%] } \\
& d t y_{i, r}^{m a t}: \quad \text { duty rate from intermediate line } i \text { for raw material } r \quad \text { [\%] } \\
& \begin{aligned}
\pi_{i, t}^{i n t}= & \sum_{e, m}\left(t p r_{m}^{i n t} \cdot\left(1-d t y_{i, e}^{i n t}\right)-v a r_{i, m}^{i n t}-f r e_{i, e}^{i n t}\right) \cdot I N T_{i, e, m, t}^{e x t}+ \\
& \sum_{r}\left(s p r_{r}^{m a t} \cdot\left(1-d t y_{i, r}^{m a t}\right)-v a r_{i, r}^{m a t}-f r e_{i, r}^{m a t}\right) \cdot M A T_{i, r, t}+ \\
& \sum_{d, m}\left(t p r_{m}^{i n t} \cdot\left(1-d t y_{i, d}^{i t d}\right)-v a r_{i, m}^{i n t}-f r e_{i, d}^{i t d}\right) \cdot I N T_{i, d, m, t}^{d i s}
\end{aligned}
\end{aligned}
$$

At the intermediate stage, revenues are generated by the sale of raw materials to external organizations and the transfer of intermediates to extrusion and dispersion lines. Production costs are the main exploitation costs. Because of the various sourcing alternatives, all PVB businesses deliver their production duty paid, i.e. freight costs and customs duties are also considered as costs to be paid by the sender.

$$
\operatorname{spr}_{s}^{d i s} \quad: \quad \text { sales price for dispersion resin } s \quad[\$ / \mathrm{kg}]
$$


$v_{d s}^{d i s}:$ production costs for dispersion resin $s$ on line $d$

$f r e_{d, s}^{d i s}:$ freight costs from line $d$ for dispersion resin $s$

$d t y_{d, s}^{d i s}:$ duty rate from line $d$ for dispersion resin $s$

$$
\pi_{d, t}^{d i s}=\sum_{s}\left(s p r_{s}^{d i s} \cdot\left(1-d t y_{d, s}^{d i s}\right)-v a r_{d, s}^{d i s}-f r e_{d, s}^{d i s}\right) \cdot D I S_{d, s, t}-\sum_{i, m} t p r_{m}^{i n t} \cdot I N T_{i, d, m, t}^{d i s}
$$

Dispersion lines generate revenues selling resins to final customers. We notice that the procurement costs for intermediates are deducted from the contribution of the dispersions business.

$$
\begin{aligned}
& s p r_{p_{e}}^{r e f}: \text { sales price for refrigerated sheets } p_{e} \quad \text { [\$/sqm] } \\
& t p p_{p_{o}}^{r e f}: \text { transfer price for refrigerated sheets } p_{o} \quad \text { [\$/sqm] } \\
& v_{e, p}^{e x t}: \text { extrusion costs for product } p \text { on line } e \text { [\$/sqm] } \\
& \operatorname{fre}_{e, p_{e}}^{r e f}: \text { freight costs from line } e \text { to final customer buying the refrigerated }[\$ / \mathrm{sqm}] \\
& \text { sheets } p_{e} \\
& f r e_{e, o}^{t s f} \quad: \quad \text { freight costs from extrusion line } e \text { to interleaving line } o \text { for refrig- } \\
& \text { erated sheets }[\$ / \mathrm{sqm}] \\
& d t y_{e, p_{e}}^{r e f}: \quad \text { duty rate from line } e \text { to a final customer's location for refrigerated [\%] } \\
& \text { sheets } p_{e} \\
& d t y_{e, o}^{t s f} \quad: \quad \text { duty rate from extrusion line } e \text { to interleaving line } o \quad[\%] \\
& \pi_{e, t}^{e x t}=\sum_{p_{e}}\left(s p r_{p_{e}}^{r e f} \cdot\left(1-d t y_{e, p_{e}}^{r e f}\right)-\operatorname{var}_{e, p_{e}}^{e x t}-f r e_{e, p_{e}}^{r e f}\right) \cdot E X T_{e, p_{e}, t}+ \\
& \sum_{o, p_{o}}\left(t p r_{p_{o}}^{r e f} \cdot\left(1-d t y_{e, o}^{t s f}\right)-v a r_{e, p_{o}}^{e x t}-f r e_{e, o}^{t s f}\right) \cdot O F L_{e, o, p_{o}, t}- \\
& \sum_{i, m} t p r_{m}^{i n t} \cdot I N T_{i, e, m, t}^{e x t}
\end{aligned}
$$

At the extrusion stage, revenues are generated by the sale of refrigerated products to final customers and the internal sale of sheets to interleaving lines. Variable production costs and procurement costs (to obtain intermediates) are the main exploitation costs. Here again, the sales are duty paid.

$$
\begin{array}{llll}
s p r_{p_{o}}^{o f l}: & \text { sales price of interleaved sheets } p_{o} & {[\$ / \mathrm{sqm}]} \\
\operatorname{var}_{o, p_{o}}^{o f l}: & \text { variable costs on line } o \text { to interleave sheets } p_{o} & {[\$ / \mathrm{sqm}]} \\
f r e_{o, p_{o}}^{o f l}: & \text { freight costs from line } o \text { for interleaved sheets } p_{o} & {[\$ / \mathrm{sqm}]} \\
d t y_{o, p_{o}}^{o f l}: & \text { duty rate from line } o \text { for interleaved sheets } p_{o} & {[\%]} \\
& & \\
\pi_{o, t}^{o f l} & =\sum_{e, p_{o}}\left(s p r_{p_{o}}^{o f l} \cdot\left(1-d t y_{o, p_{o}}^{o f l}\right)-\operatorname{var}_{o, p_{o}}^{o f l}-\operatorname{tpr}_{p_{o}}^{r e f}-f r e_{o, p_{o}}^{o f l}\right) \cdot O F L_{e, o, p_{o}, t}
\end{array}
$$

At the offline stage, revenues are generated by the sales of interleaved film rolls to final 
customers. The cost structure does not differ from the one at the extrusion stage, so far the interleaving lines have to carry variable production costs, procurement costs, freight costs and customs duties.

\section{Constraints and related technical parameters}

\section{Capacities}

The total production capacities of the manufacturing lines are expressed in days, while production rates are given in kilograms or square meters per day. Taking into account these parameters, constraints 6 to 9 ensure that the total time required to produce intermediates, raw materials, dispersion resins, refrigerated and interleaved sheets does not exceed the available capacities. To avoid divisions by 0 , only the products manufacturable on the line are summed on the lefthand side of the capacity constraints. For this purpose, we use the product subsets $M_{i}$ and $R_{i}$ (intermediate lines), $S_{d}$ (dispersion lines), $P_{e}$ (extrusion lines) and $P_{o}$ (interleaving lines).

$$
\begin{aligned}
& \text { cap int : capacity of intermediate line } i \text { in quarter } t \quad \text { [days] } \\
& k g d_{i, m}^{i n t}: \text { production rate of intermediate } m \text { on line } i \quad \text { [kg/day] } \\
& k g d_{i, r}^{\text {mat }}: \quad \text { production rate of raw material } r \text { on line } i \quad \text { [kg/day] } \\
& \sum_{m \in M_{i}} \frac{\sum_{e} I N T_{i, e, m, t}^{e x t}+\sum_{d} I N T_{i, d, m, t}^{d i s}}{k g d_{i, m}^{i n t}}+\sum_{r \in R_{i}} \frac{M A T_{i, r, t}}{k g d_{i, r}^{\text {mat }}} \leq c a p_{i, t}^{i n t} \quad \forall i, t \\
& \operatorname{cap}_{d, t}^{d i s}: \text { capacity of dispersion line } d \text { in quarter } t \quad \text { [days] } \\
& k g d_{d, s}^{d i s}: \text { production rate of dispersion resin } s \text { on line } d \quad \text { [kg/day] } \\
& \sum_{s \in S_{d}} \frac{D I S_{d, s, t}}{k g d_{d, s}^{d i s}} \leq c a p_{d, t}^{d i s} \quad \forall d, t
\end{aligned}
$$$$
\operatorname{cap}_{e, t}^{e x t}: \text { capacity of extrusion line } e \text { in quarter } t \quad \text { [days] }
$$$$
s q d_{e, p}^{\text {ext }}: \text { extrusion rate of sheets } p \text { on line } e \quad \text { [sqm/day] }
$$$$
\sum_{p_{e} \in P_{e}} \frac{E X T_{e, p_{e}, t}}{s q d_{e, p_{e}}^{e x t}}+\sum_{o, p_{o} \in P_{e}} \frac{O F L_{e, o, p_{o}, t}}{s q d_{e, p_{o}}^{e x t}} \leq c a p_{e, t}^{e x t} \quad \forall e, t
$$

$\operatorname{cap}_{o, t}^{o f l} \quad: \quad$ capacity of interleaving line $o$ in quarter $t$

$s q d_{o, p_{o}}^{o f l}:$ interleaving rate of products $p_{o}$ on line $o$

$$
\sum_{e, p_{o} \in P_{o}} \frac{O F L_{e, o, p_{o}, t}}{s q d_{o, p_{o}}^{o f l}} \leq c a p_{o, t}^{o f l} \quad \forall o, t
$$




\section{Demand}

Constraints 10 to 13 have to ensure that the produced quantities meet a customer's demand. On the mid-term, Solutia has the possibility to support some specific products which turn out to be very profitable and to reduce the sales of less beneficial items. In this case, the sales might, if allowed to, move within a given lower $l b$ and upper bound $u b$.

$$
\begin{aligned}
& \operatorname{dem}_{r, t}^{\text {mat }}: \quad \text { demand for raw material } r \text { in quarter } t \quad[\mathrm{~kg}] \\
& \operatorname{dem}_{s, t}^{\text {dis }}: \text { demand for dispersion resin } s \text { in quarter } t \quad \text { [kg] } \\
& \operatorname{dem}_{p_{e, t}}^{r e f}: \text { demand for extruded-only product } p_{e} \text { in quarter } t \quad \text { [sqm] } \\
& \operatorname{dem}_{p_{o}, t}^{o f l}: \text { demand for interleaved product } p_{o} \text { in quarter } t \quad \text { [sqm] } \\
& d e m_{r, t}^{\text {mat }} \cdot l b_{r, t}^{\text {mat }} \leq \sum_{i} M A T_{i, r, t} \leq d e m_{r, t}^{\text {mat }} \cdot u b_{r, t}^{\text {mat }} \quad \forall r, t \\
& d e m_{s, t}^{d i s} \cdot l b_{s, t}^{\text {dis }} \leq \sum_{s} D I S_{d, s, t} \leq \operatorname{dem}_{s, t}^{\text {dis }} \cdot u b_{s, t}^{\text {dis }} \quad \forall s, t \\
& \operatorname{dem}_{p_{e}, t}^{r e f} \cdot l b_{p_{e}, t}^{r e f} \leq \sum_{e} E X T_{e, p_{e}, t} \leq d e m_{p_{e}, t}^{r e f} \cdot u b_{p_{e}, t}^{r e f} \quad \forall p_{e}, t \\
& \operatorname{dem}_{p_{o}, t}^{o f l} \cdot l b_{p_{o}, t}^{o f l} \leq \sum_{e, o} O F L_{e, o, p_{o}, t} \leq \operatorname{dem}_{p_{o}, t}^{o f l} \cdot u b_{p_{o}, t}^{o f l} \quad \forall p_{o}, t
\end{aligned}
$$

\section{Sourcing requirements}

Constraints 14 to 17 ensure flow continuity between intermediate lines and extrusion/dispersion lines. Sourcing requirements for the production of dispersion resins and the extrusion of sheets are also encompassed in these flow constraints.

$$
\begin{aligned}
& r e q_{m, p}^{\min }: \quad \text { minimum sourcing requirements of intermediate } m \text { for product } p \quad[\mathrm{~kg} / \mathrm{sqm}] \\
& r e q_{m, p}^{\max }: \quad \text { maximum sourcing requirements of intermediate } m \text { for product [kg/sqm] } \\
& p \\
& r e q_{p}^{r e s}: \text { sourcing requirements of resins for product } p \quad[\mathrm{~kg} / \mathrm{sqm}] \\
& r e q_{m, s}^{d i s} \quad: \quad \text { sourcing requirements of intermediate } m \text { for dispersion resin } s \quad \text { [kg/sqm] } \\
& \beta_{e, p, t}^{e x t} \quad \text { : sourcing binary indicating from which extrusion line } e \text { a product [bin] } \\
& p \text { is sourced in quarter } t \\
& I N T_{i, d, m, t}^{d i s}=\sum_{d, s} D I S_{d, s, t} \cdot r e q_{m, s}^{d i s} \quad \forall i, m, t
\end{aligned}
$$

At the extrusion stage, intermediates, rb resins, solvent resins and plasticizers, are required as input for the production of dispersions and sheets. As rb resins can be substituated to solvent resins, the sourcing requirements of these intermediates for a product $p$ can vary between a lower $\left(r e q_{m, p}^{\min }\right)$ and an upper $\left(r e q_{m, p}^{\max }\right)$ bound (eq. 15, 16). However, the sum of these two material sources needs to be equal to a total resin amount $r e q_{p}^{r e s}$ (see eq. 17). As the proportion of plasticizers is fixed, the minimum sourcing requirement for this intermediate will be equal to the maximum one. For this reason, equations 15 and 16 only apply for the intermediate subset $M_{r}$ depicting both $\mathrm{rb}$ and solvent resins 


$$
\begin{array}{rll}
I N T_{i, e, m, t}^{e x t} & \leq \sum_{p_{e}} r e q_{m, p_{e}}^{\max } \cdot E X T_{e, p_{e}, t}+\sum_{o, p_{o}} r e q_{m, p_{o}}^{\max } \cdot O F L_{e, o, p_{o}, t} \quad \forall i, e, m \in M_{r}, t \\
I N T_{i, e, m, t}^{e x t} & \geq \sum_{p_{e}} r e q_{m, p_{e}}^{\min } \cdot E X T_{e, p_{e}, t}+\sum_{o, p_{o}} r e q_{m, p_{o}}^{\min } \cdot O F L_{e, o, p_{o}, t} \quad \forall i, e, m \in M_{r}, t \\
\sum_{i, m_{r}} I N T_{i, e, m_{r}, t}^{e x t} & =\sum_{p_{e}} r e q_{p_{e}}^{r e s} \cdot E X T_{e, p_{e}, t}+\sum_{o, p_{o}} r e q_{p_{o}}^{r e s} \cdot O F L_{e, o, p_{o}, t} & \forall e, t
\end{array}
$$

For sake of complexity minimization and inventory planning purposes, we introduce a single sourcing variable $\beta_{e, p, t}^{e x t}$ which ensures that a specific customer/formulation combination can only be sourced from one extrusion line in each quarter (see eq. 20).

$$
\begin{aligned}
E X T_{e, p_{e}, t} & \leq\left(\operatorname{dem}_{p_{e}, t}^{r e f} \cdot u b_{p_{e}, t}^{r e f}\right) \cdot \beta_{e, p_{e}, t}^{e x t} \quad \forall e, p_{e}, t \\
\sum_{o} O F L_{e, o, p_{o}, t} & \leq\left(\operatorname{dem}_{p_{o}, t}^{i t l} \cdot u b_{p_{o}, t}^{i t l}\right) \cdot \beta_{e, p_{o}, t}^{e x t} \quad \forall e, p_{o}, t \\
\sum_{e} \beta_{e, p, t}^{e x t} & =1 \quad \forall p, t: p \in\left(P_{e} \cup P_{o}\right)
\end{aligned}
$$

\section{Logical constraints}

When a product does not belong to the manufacturable subset of a specific line, its related production rate is equal to 0 . In this case, the product has not been entered into the left-hand side of the capacity constraint. Therefore, it is necessary to ensure that such combinations are also null in order to avoid infeasible solutions. Equations 21 to 26 forbid the production of infeasible products.

$$
\begin{array}{rlrl}
I N T_{i, e, m, t}^{e x t} & =0 & & \forall i, e, m \notin M_{i}, t \\
I N T_{i, d, m, t}^{\text {dis }}=0 & & \forall i, d, m \notin M_{i}, t \\
M A T_{i, r, t}=0 & & \forall i, r \notin R_{i}, t \\
D I S_{d, s, t}=0 & & \forall d, s \notin S_{d}, t \\
E X T_{e, p_{e}, t} & =0 & & \forall e, p_{e} \notin P_{e}, t \\
O F L_{e, o, p_{o}, t} & =0 & & \forall e, o, p_{o} \notin P_{e}, p_{o} \notin P_{o}, t
\end{array}
$$




\section{PaASTER RIPZZDIATES \\ MANUFACTURING}

Internatigng:dథrsnal of Production Research EXTRUSION
SHEETS

INTERLEAVING

demand Trenton, MI

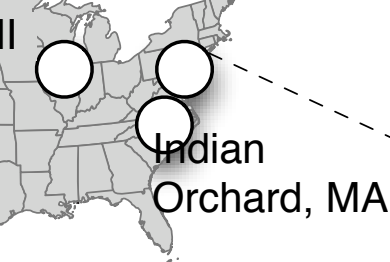

Work-in-process 


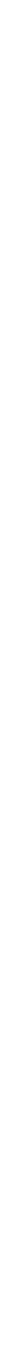




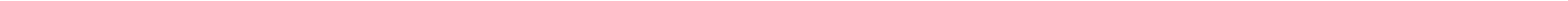




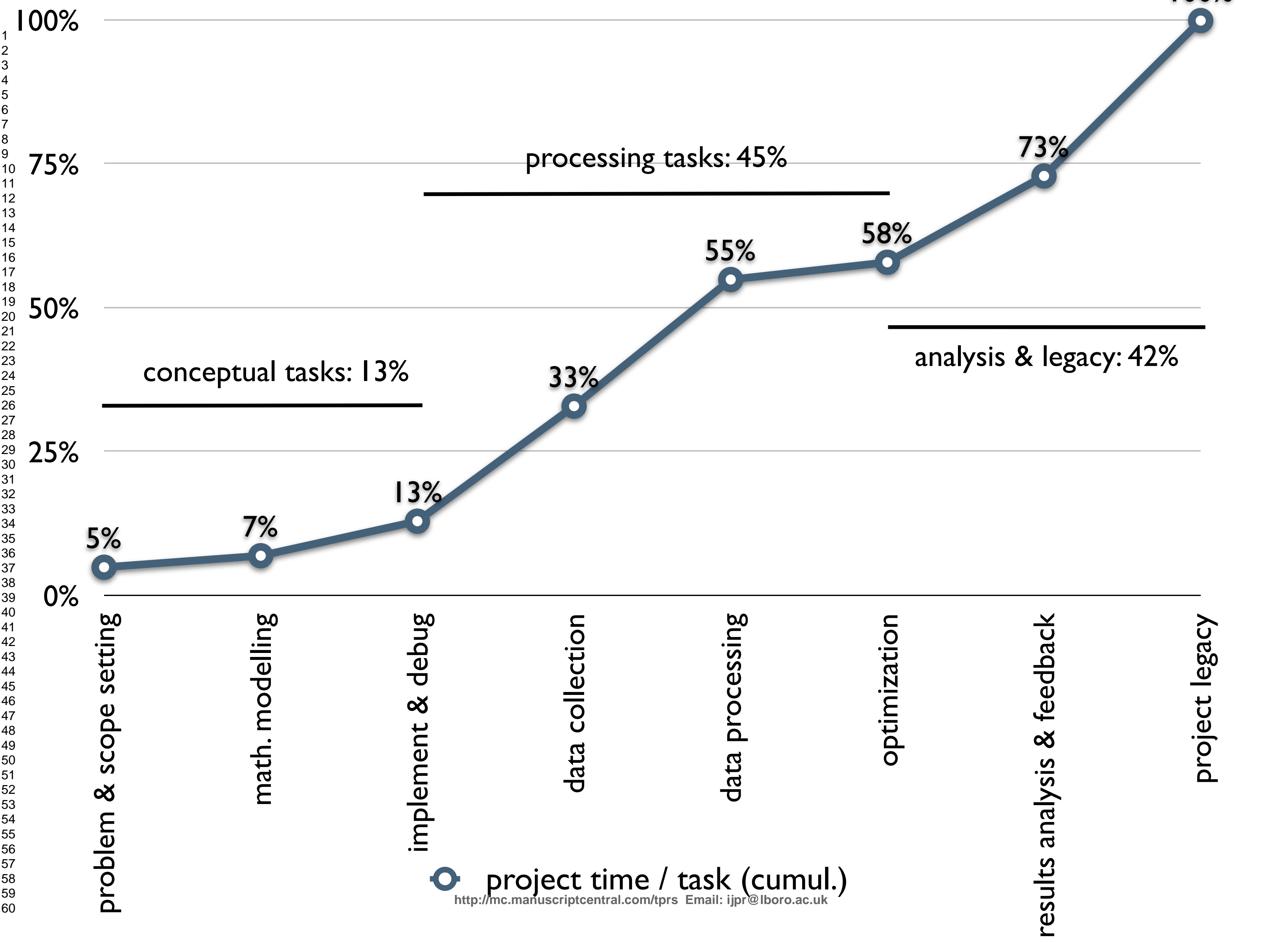


Extrusion line 1 Ghent, BE

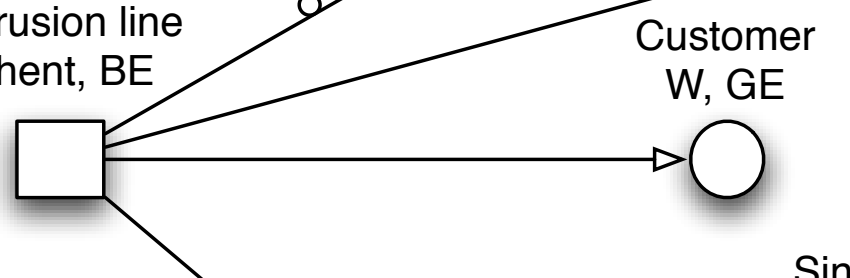

DC

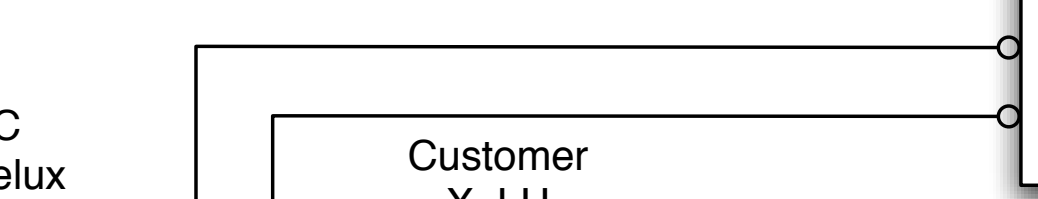

Shipments table (ERP)

Shipment ID

Origin node ID

Destination node ID

Material ID

Transport mode ID

Total shipment costs 


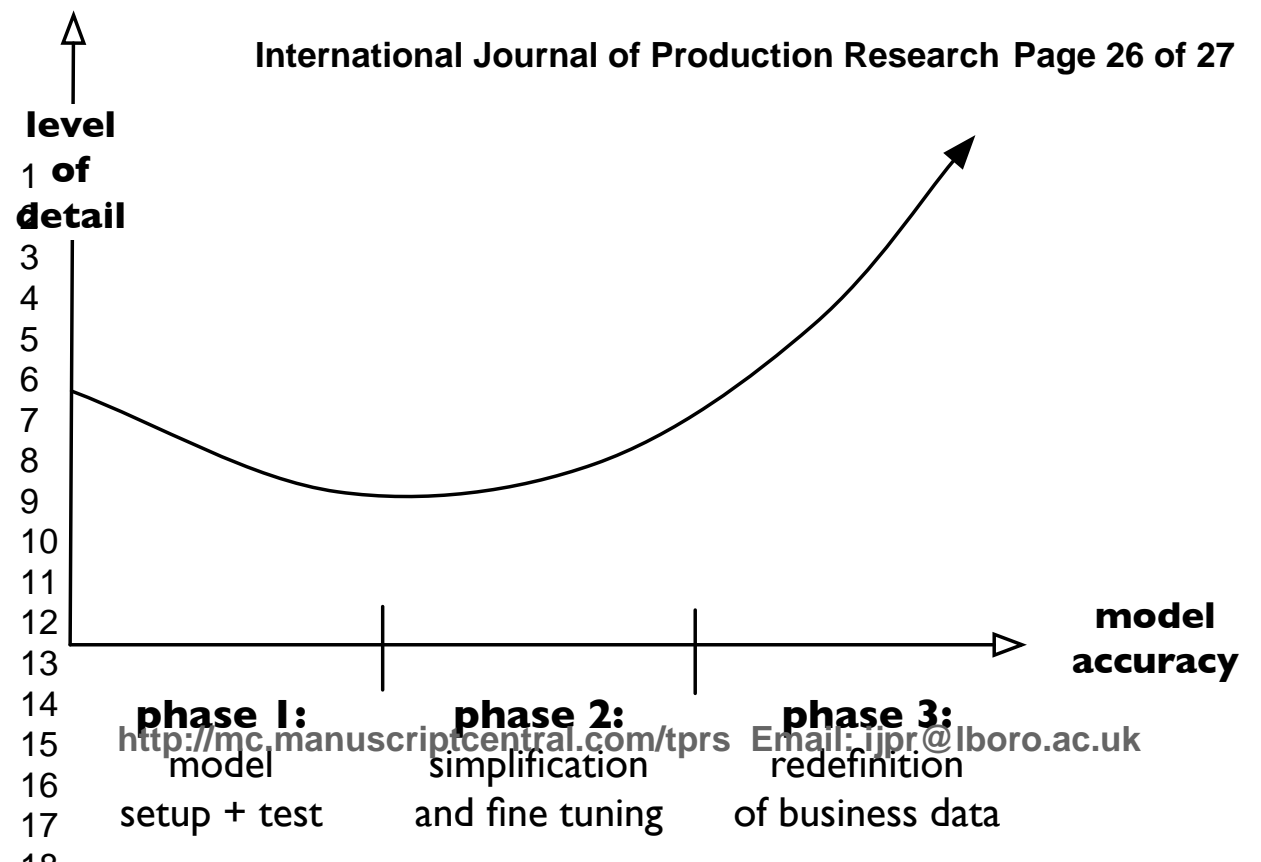




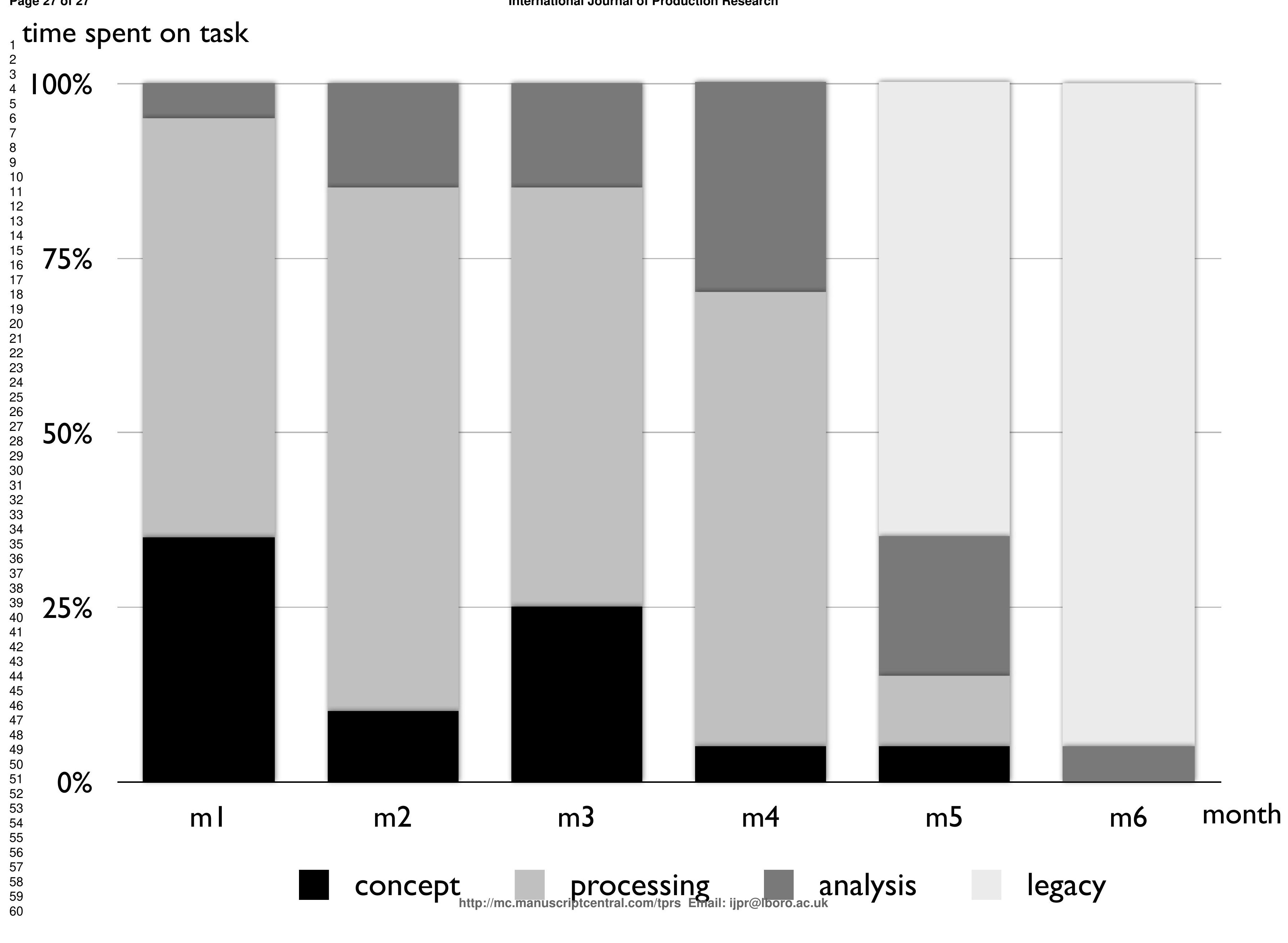

